\title{
Critical Discourse Analysis on Chinese Racial Pride Underlying the Malaysian National Identity in "Proud to be born a Chinese"
}

\author{
Khoo Wei Cyn (Corresponding author) \\ School of Education, Languages and Communications, Wawasan Open University, 54, Jalan Sultan Ahmad Shah, 10050 Penang, Malaysia \\ E-mail: kwc3_PG@student.wou.edu.my
}

Malini Ganapathy

School of Languages, Literacies and Translation, Universiti Sains Malaysia, Minden, Gelugor, 11800 Penang, Malaysia E-mail: malinik@usm.my

Doi:10.7575/aiac.alls.v.7n.5p.162

URL: http://dx.doi.org/10.7575/aiac.alls.v.7n.5p.162
Received: 28/06/2016

Accepted: $24 / 08 / 2016$

\begin{abstract}
The ideology of Chinese racial pride in an online essay "Proud to be born a Chinese" by Dr. Chan-Lui Lee is described and analysed by using the sociocognitive approach to critical discourse analysis (CDA). The research design is based on the notion that Chinese racial pride is a tool to persuade Chinese Malaysians to prioritise their Chinese racial identity over the Malaysian national identity, leading to national disunity and racial fissures in society. This notion runs parallel to the concept of the dynamicity and fluidity of the construction of identity, as explored by Jones, McEwen and Abes in their Reconceptualised Model of Multiple Identities (2007). As the degree to which Malaysians identify with the national identity over other group identities determines the success of national unity (Liu et al, 2002), Dr. Chan-Lui Lee's essay provides insight into the overall success of national unity in Malaysia. "Proud to be born a Chinese" is analysed through three components: the discursive, cognitive and social components, which not only confirm that the essay prioritises Chinese racial identity over Malaysian national identity using Chinese racial pride, but also that the essay and its strategies are a response to the socio-political circumstances in Malaysia and the creation of neonationalist identities in the relatively new nations of Southeast Asia.
\end{abstract}

Keywords: critical discourse analysis, sociocognition, racial pride, racial identity, national identity, national unity, multiple identities, southeast asia, neo-nationalism, socio-politics

\section{Introduction}

\subsection{Importance of "Proud to be born a Chinese" on Identity}

In 2013, an online essay became the staple of discussions throughout social media and websites in Malaysia. Titled "Proud to be born a Chinese," it was attributed to Dr. Chan-Lui Lee, a former Malaysian who now lives in Melbourne. This essay struck a chord with Malaysians, posted in ten different media and shared across Malaysia for thousands of times. A rewritten version of it was published in Malaysiakini (Rajaratnam, 2015), and entertainment website World of Buzz (2015) called the meme "inspiring". Whilst it is evident that the essay is written about Chinese racial pride, this ideology has significant social effects in Malaysia, a country that prides itself on multiculturalism. Due to the dynamic nature of identity, it is a troubling concern if a group identity such as race is prioritised over the national identity as it can destabilise racial relations in Malaysia and affect the success of national unity.

Using the perspective of critical discourse analysis (CDA), this report investigates how the essay "Proud to be born a Chinese" prioritises racial identity above national identity with the use of Chinese racial pride as its ideology. Central to the research process was the identification and examination of discursive, cognitive and social components that comprised the essay. Whilst the discursive components communicated the message that the Chinese race is superior to other races, the cognitive and social components of the text were analysed to put that message in the context of a Malaysian national identity which is juxtaposed with Chinese racial identity. The report then identifies macropropositions, local meanings and specific linguistic realisations that correspond to the function of the discursive component of the text, followed by the examination of the context model and event model that provided contextual information as well as an ideological analysis of "Proud to be born a Chinese".

One of the concepts used in this study is the reconceptualised Model of Multiple Dimensions of Identity by Jones, McEwen and Abes (2007), which explains how each individual constructs their identity from a combination of dimensions. These dimensions are identity markers such as race, gender, sexuality, religion, ethnicity, political affiliation, geography, socioeconomic class and more. In the context of Malaysia, another dimension that affects the 
construction of identity for Malaysians is the national identity, which has been stressed upon all citizens to foster national unity between the many races and cultures in Malaysia (Liu et al, 2002). The construction of identity, however, is not fixed. The hierarchy of dimensions in the order of priority or significance is subject to contextual influences, so constructions of identity are dynamic responses to events and the environment of the individual (Jones, McEwen \& Abes, 2007).

Teun van Dijk's sociocognitive approach to CDA (2015) forms the foundation for this research to evaluate the discursive, cognitive and social components of a text that affects the construction of identity in the Chinese Malaysian reader of "Proud to be born a Chinese". This perspective analyses the Chinese racial pride as its ideology, and how the essay has the potential to describe or trigger socio-political factors (Jones, McEwen \& Abes, 2007) that may cause the prioritisation of the Chinese racial identity over Malaysian national identity.

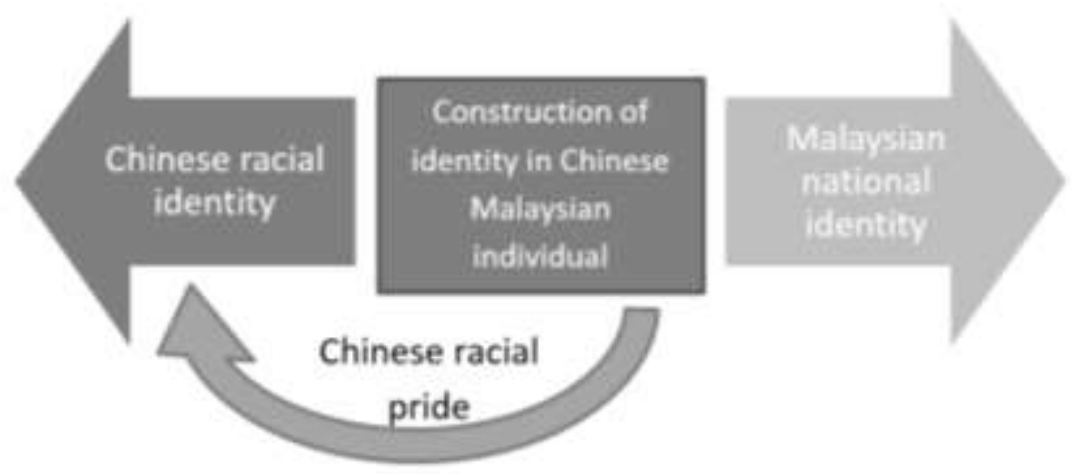

Figure 1. Conceptual framework for the construction of identity in Chinese Malaysians

Using van Dijk's sociocognitive approach (2015) in combination with the reconceptualised Model of Multiple Dimensions of Identity (Jones, McEwen and Abes, 2007), this report identifies the use of language in conjunction with socio-political factors that cause Chinese Malaysian readers of "Proud to be born a Chinese" to associate Chinese racial pride with positive attitudes, leading to the marginalisation of the Malaysian national identity.

\subsection{Implications of Study}

This report addresses the gap in existing literature that analyses the effects of language on the construction of identity, by persuading individuals to prioritise certain dimensions of identity over others. There have been several CDAs regarding identity (Abdullah, 2004; Ainsworth \& Hardy, 2004; Hernandez, 2008; Barker, 2001; Budianta, 2000), but so far there has yet to be a report that has broached the topic of identity utilising the concept of multiple identities.

It would also serve as a pioneering study in merging the question of the Malaysian Malaysia identity (Abdullah, 2004) with the question of racial identity as the ideology for a racial group (Thatcher \& Patel, 2011 as cited by Feitosa, Salas \& Salazar, 2012).

\section{Literature Review}

\subsection{Related Studies}

In an analysis of Chinese socio-political manoeuvers and their position in Malaysia as a minority race, Heng (1996) explained Sino-Malay relations in post-independence Malaysia and the various concepts behind Chinese nationalism; including the differences in Chinese political strategies which could be categorised as either Chinese-oriented or Malayan-oriented. In the examination of the Chinese identity in Malaysia, Heng identified four dimensions: Confucian values and elements of Chinese cultural heritage, language, diet, and adaptation to Malay hegemony. However, this study answered little with regards to the question of the Chinese Malaysian identity, as its primary focus was on the political conflict between the Malay Malaysians and the Chinese Malaysians.

Callahan's (2003) was much more relevant to my perspective of the identity of the local Chinese diaspora. By contrasting principles of nationalism and cosmopolitanism in the identity politics of the Chinese diaspora of Thailand, Callahan made very salient points towards the perceived dichotomy in the definitions of "Chinese-ness" and "Thainess". He noted that in postcolonial Southeast Asia, the Chinese diaspora were considered an "ethnic problem". The Chinese diaspora was similar to Jewish communities in Europe as they were considered the "pariah entrepreneur group" that had benefited from the policies of European imperialism. Therefore, in postcolonial Southeast Asian countries, politics surrounding the Chinese communities were questions of their loyalty to their Chinese homeland or to the nation they had adopted. Moreover, in their recovery from their postcolonial history, these nations forged their postcolonial identities, a national self, using the Chinese diaspora as the "essential outsider". In Thailand, which was the site of Callahan's study, the identity "Sino-Thai" was considered a contradiction upon itself because Thai nationalism was an anti-Chinese project. This research piece contains valuable insight into my study because it explains the circumstances surrounding the manmade dichotomy between Southeast Asian national identities and the Chinese cosmopolitan identity that was linked through race.

Budianta's (2007) study revolves around the dichotomy between Indonesia's national culture and American pop culture, 
which was introduced to the country as a result of globalisation. Thus Budianta analysed the discursivity of this phenomenon which happened during the $1997-1998$ economic crisis. Whilst in terms of regional context this study may have more similarities to my project, it did not utilise CDA and did not concern itself with the subject of racial pride and identity; but rather to the question of national culture, and racial and cultural politics. Three years after Budianta's study, De Polo (2010) conducted a CDA on the written texts of four African American students to look for textual dissonance, a result that he proposed resulted from the conflict between their African American discoursal identity and the dominant identity of academic writing. This article was an example of a social research project that utilised a similar approach of qualitative research; unfortunately, it did not analyse the texts in terms of racial pride with relation to national identity and unity, which are the fundamental concepts in my report.

\subsection{Identity Politics, Social Identity and Group Identity}

Identity politics is defined by Klandermans (2014) as the point when a collective identity becomes the focus of a power struggle that involves social groups in a grapple over societal power structures. In the context of this study, it is the struggle between ideologies of Chinese racial identity and Malaysian national identity in coming to the forefront of the construction of identity. The manipulation of ideologies corresponding to identity politics using racial pride will be part of the focus of this study.

Social identity refers to an individual's sense of belonging to their social circle, otherwise known as group memberships (Feitosa, Salas \& Salazar, 2012). It is also referred to as collective identity or group identity, and this concept of identity has helped to explain social phenomena such as peer pressure and intergroup prejudice (Jackson \& Smith, 1999; cited by Feitosa, Salas \& Salazar, 2012). The challenge that group identity poses is that individuals with a strong sense of group identity create "faultlines" in culturally diverse environments (Lau \& Murnighan, 1998; Thatcher \& Patel, 2011 as cited by Feitosa, Salas \& Salazar, 2012). This is especially an important issue to address in multicultural societies such as Malaysia for its potential to cause intergroup conflicts in such situations.

\subsection{Dynamicity and Multiplicity of Identity}

The fluidity of personal identity is illustrated through Jones, McEwen and Abe's (2007) reconceptualised Model of Multiple Dimensions of Identity. Various dimensions of identity, such as group memberships and social identities contribute, to the formation of an individual's personal identity. Close to the core of self-perceptions is racial identity, which will be elaborated further in the context of the study.

The relationship and dynamics between these dimensions are subject to contextual influences, and filtered through by the individual's meaning-making capacity. These contextual influences include socio-political conditions, which can affect the relationships between the dimensions of an individual's identity.

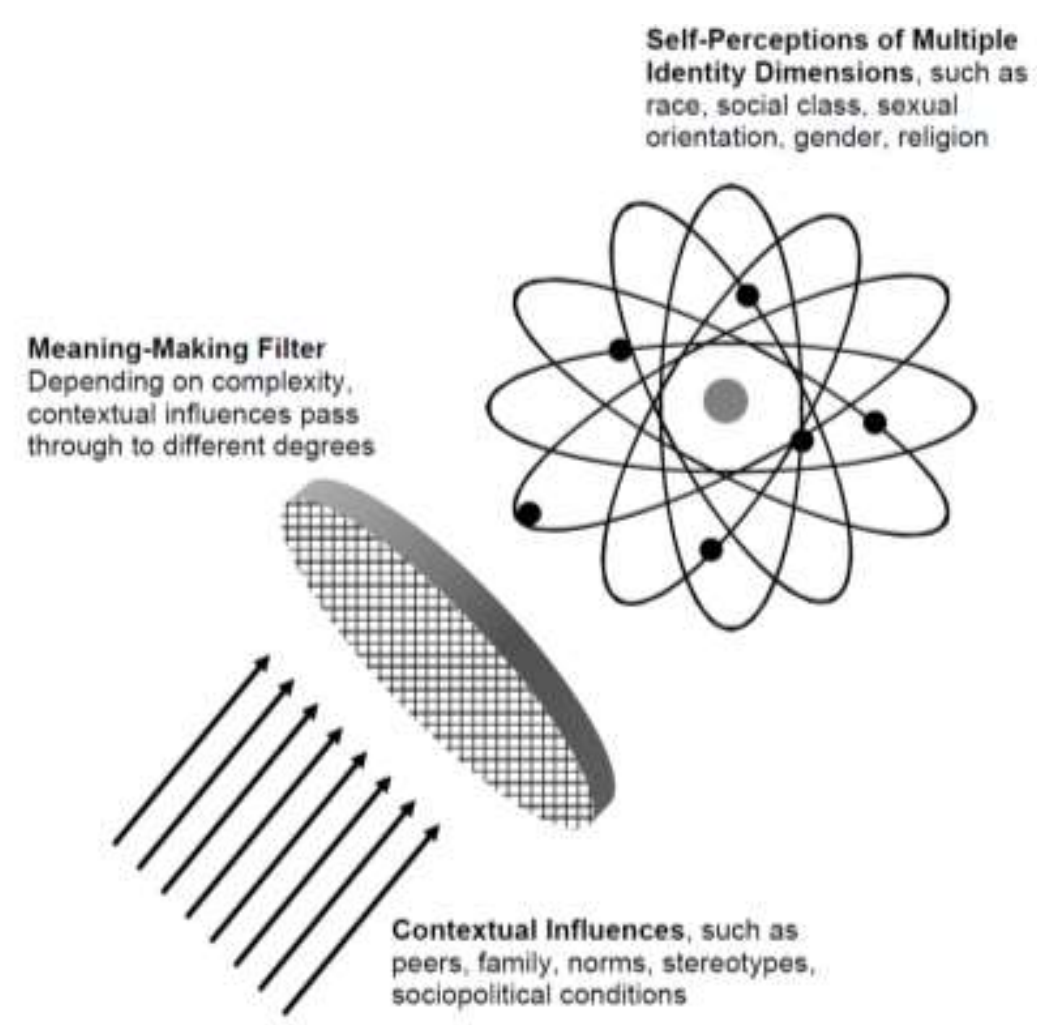

Figure 2. Reconceptualised Model of Multiple Identities (Jones, McEwen and Abe, 2007)

\subsection{Racial vs national identity and national unity in Malaysia}

In 2009, Wodak, de Cillia and Reisigl wrote about the discursive construction of national identity as a collection of common interests that have been internalised by individuals through the process of socialisation. This may also include common emotional attitudes and behaviours that are inclusive and oriented towards solidarity for fellow members, and 
exclusive towards "outsiders". Depending on the extent of identification, it is part of the construction of identity in the individual.

Abdullah (2004) proposed a discursive model to analyse Malaysia's national identity, and analysed the Malaysian former prime minister Tun Dr. Mahathir's ideologies of national identity. He noted that the era of Mahathirism saw a dichotomy between the argument for assimilation and the argument for integration of racial minorities in the country. Eventually, the idea of assimilation was discarded in favour of another idea: creating a "Malaysian Malaysia" identity by lessening the prioritisation of ethnic identity. Abdullah (2004) then concluded that he was in favour of the strategic positioning of nationalist and national ideologies on a continuum to negotiate the multiple facets of Malaysia's national identity. Moreover, a representative sampling of discourses - akin to a quantitative approach - and the use of a variety of semiotic modalities would ensure the quality of a discursive analysis on national identity.

Therefore, the definition of the Malaysian national identity that is used in this study adheres to Abdullah's (2004) exploration of the Malaysian national identity, which is imbued with Lim Kit Siang's identity leitmotiv of a "Malaysian Malaysia" where racial minorities reduce their sense of racial identity in favour of a common Malaysian national identity.

\subsection{Linking Hypothesis to Research Design}

In order to examine "Proud to be born a Chinese" with regards to Chinese racial pride, Chinese racial identity and Malaysian national identity thoroughly, van Dijk's sociocognitive CDA (2015) provides the foundation for analysing the text in three different layers: the discourse level, the cognitive level and the social level. Identifying the discursive component in the text that communicates the idea that the Chinese race is superior to other races in Malaysia requires the examination of macropropositions, local meanings and specific linguistic realisations that reinforce Chinese pride in the text. This constitutes the first step of the research process.

Following the examination of the discursive component is the cognitive component, which uses van Dijk's method (2015) of context models and event models that are constructed from the reading of the text. This step contextualizes the information gained from the analysis of the discursive component by comparing its contents with the environment and socio-political factors that created it. The last procedure that follows is the analysis of the social component of "Proud to be born a Chinese", which will identify the dominant ideology used throughout the essay and provide indications to the social impact that the text has on its readers and society.

With the results of the analysis on discursive, cognitive and social components of the essay complete, the mechanisms of how "Proud to be born a Chinese" uses Chinese racial pride as its ideology for Chinese racial identity to take precedence over Malaysian national identity are better understood, as well as the social implications for the essay's success as an internet meme.

\section{Method}

\subsection{Research Design}

As a qualitative research project that utilises the framework of descriptive case studies, the research process of this report is different from most other studies typical of social research. This is because the process is circular and loops back on itself; theory informs the method of analysis upon the text, and the resulting data is examined of its assumptions using the theory.

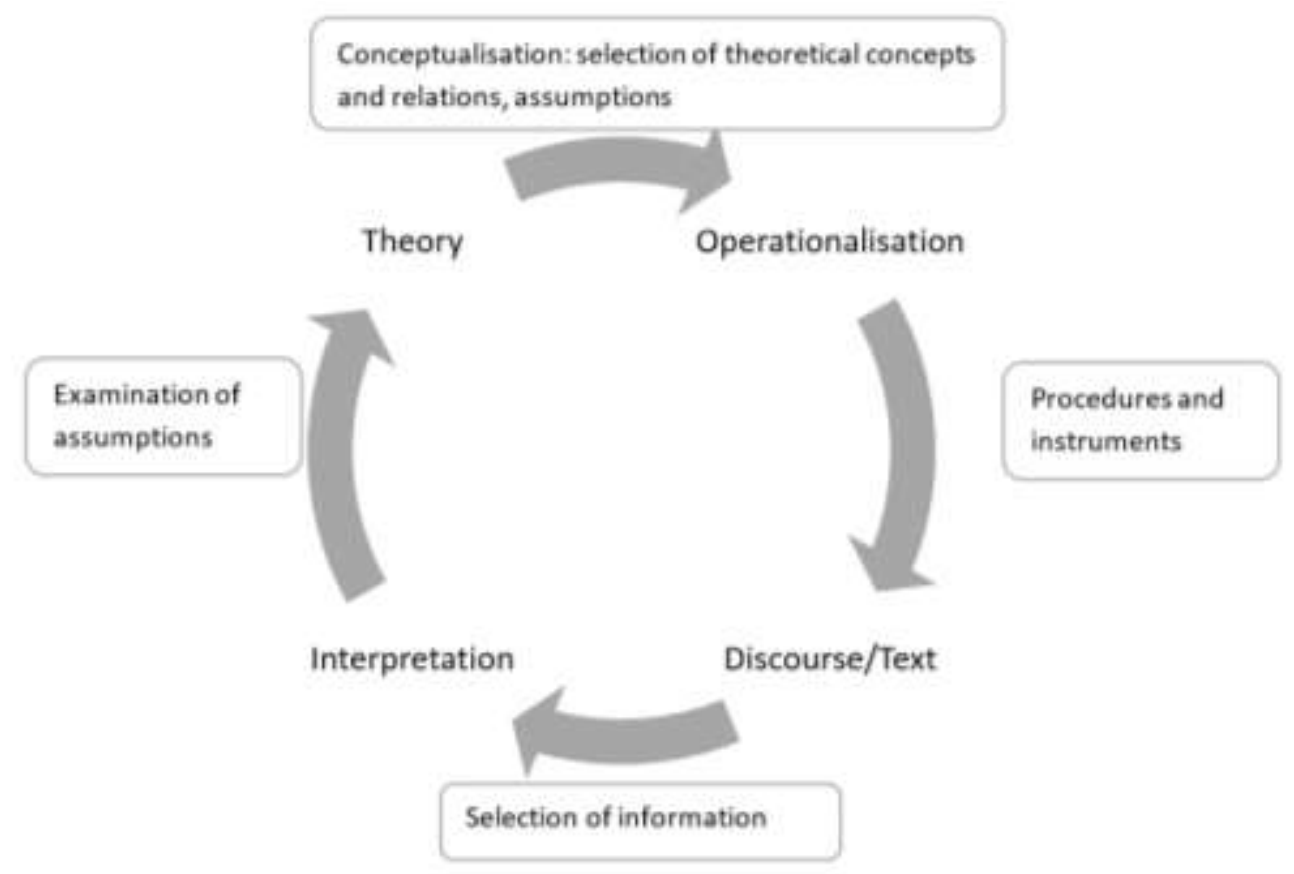

Figure 3. Research design for CDA of "Proud to be born a Chinese" (adapted from Wodak and Meyer, 2001) 
Figure 3 illustrates the empirical research process of discourse analysis, and was adapted from Wodak and Meyer's (2001) book. As observed in the illustration, mediating theory and text are the operationalisations of the theory and the interpretation of the text. The concepts and assumptions expected of the text then contribute to the selection of data that supports these assumptions before they are examined under theory.

\subsection{Instrumentation}

For instrumentation, this study uses Teun A. van Dijk's sociocognitive approach to CDA (van Dijk, 2015) in order to analyse Dr. Chan Lui Lee's essay, "Proud to be born a Chinese." The sociocognitive method revolves around the three factors that influence the text: discourse, cognition and society. In the following diagram, the relationship between these three factors are explained.

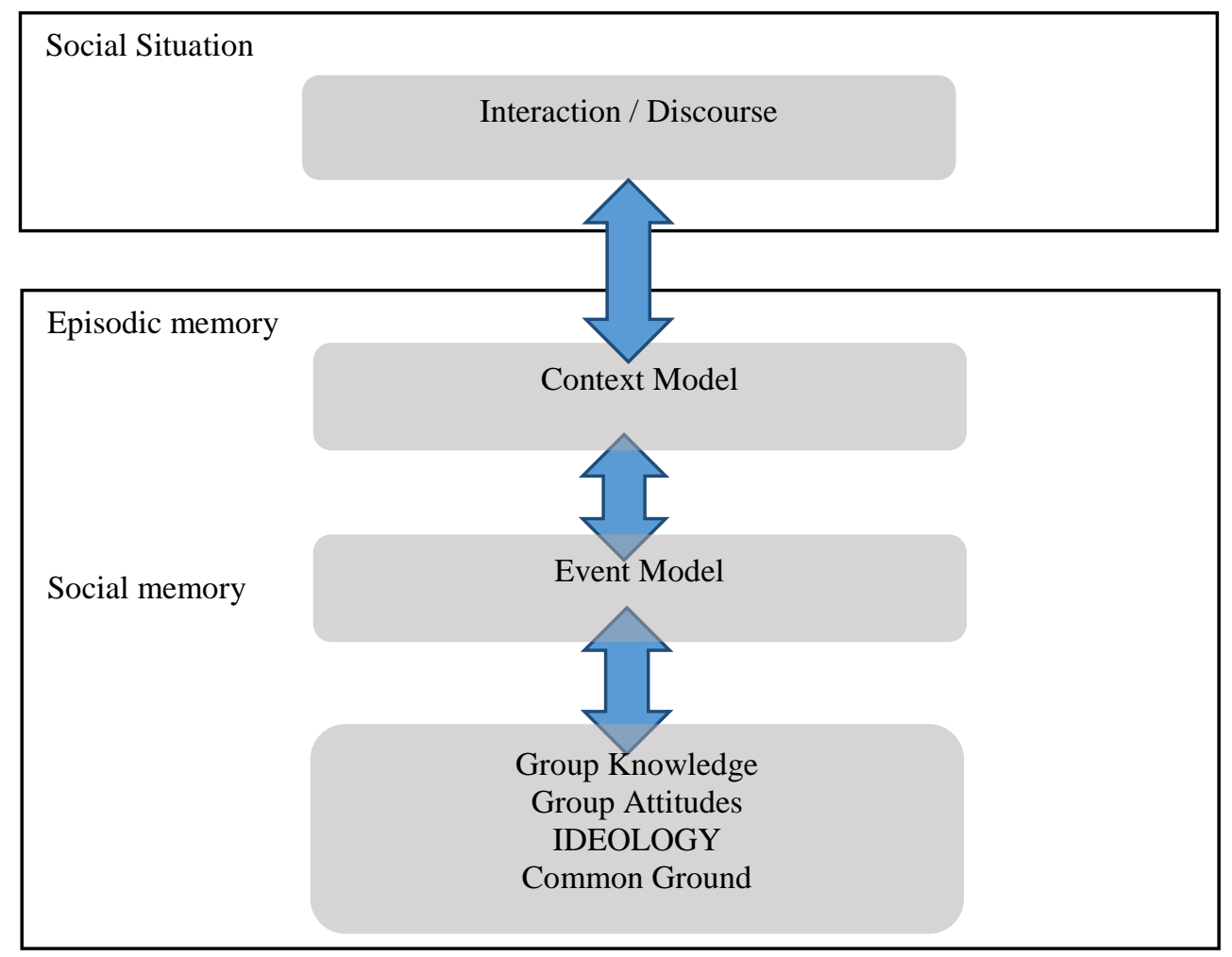

Figure 4. van Dijk's (2013) sociocognitive approach to CDA

As seen in the figure above, the factors are linked by a combination of textual features, mental models (context and event models) and ideologies. These facilitate the understanding of the condition of discourse, cognition and society that has given rise to the text itself.

Firstly, the macropropositions, propositions, local meanings and specific linguistic realisations were retrieved from the text, constituting for the analysis of the discursive component of the essay. This is followed by the analysis of the cognitive component of the text, which was achieved via the context model and event model.

Event models and context models are types of mental models formed by the episodic memory of the creators and consumers of the text. Where event models are the personal representations of events as generally understood or believed from the text, context models are directed specifically at the circumstances and situation surrounding the production and reproduction of the text itself. Mental models are unique for each individual as no two people can perceive the exact same mental model of any particular situation or event.

The schema of the event model is relatively general, consisting of several aspects: setting, participants, event/action, circumstances and most importantly, the general opinion of Chinese Malaysians towards the event as perceived in the essay.

In comparison, the schema of the context model is a lot more detailed, as given by van Dijk (1999) below:

Situation

1. Setting

\subsection{Time}

1.2. Location

1.2.1. Props

1.3. Circumstances 
2. Events

\subsection{Participants}

2.1.1. Roles

2.1.1.1. Social Roles

2.1.1.2. Interactional Roles

\subsubsection{Communicative Roles}

\subsection{Action/Discourse}

\subsubsection{Action types, Genres}

\subsection{Cognition}

\subsubsection{Aims, goals or purposes}

\subsubsection{Knowledge}

\subsubsection{Opinions}

\subsubsection{Emotions}

Thereafter, the social component of the essay was investigated using an ideology analysis. The social component of the sociocognitive approach relates to how the messages embedded in the essay are reproduced in consumers of the text, and reverberate into society. This is why the social component is a very important part of the study; it determines and measures the effect of ideologies in "Proud to be born a Chinese" as having influenced the facets of identity in Chinese Malaysians. Its schema (2013) is as follows:

1. Membership: Who are we? Who belongs to us? Who can be admitted?

2. Activities: What are we doing, planning? What is expected of us?

3. Aims: Why are we doing this? What do we want to achieve?

4. Norms: What is good or bad, allowed or not in what we do?

5. Relations: Who are our friends or enemies? Where do we stand in society?

6. Resources: What do we have that others don't? What don't we have that others do?

Concluding the tools of instrumentation that are utilised in this study is the use of the ideological square in analysing the contrast of Chinese racial pride juxtaposed with the Malaysian national identity. The schema of the ideological square is given by van Dijk (2013) as:

1. Emphasize positive things about Us

2. Emphasize negative things about Them

3. De-emphasize negative things about Us

4. De-emphasize positive things about Them

\subsection{Data Collection and Analysis}

Once adequate information was collected from applying the theories of sociocognitive CDA to the text of "Proud to be born a Chinese", interpretation of assumptions and data gathered from the text was carried out. The data was then analysed according to the paradigms as outlined in the research questions, and related back to the information that has been gathered from the literature review as well as the defining concepts that ground this report.

Whilst the attribution of positive attitudes to the Chinese race and culture is revealed with the analysis of the discursive component, the cognitive and social component analysis of the essay uncovers the extent of prioritisation of Chinese racial identity over the Malaysian national identity.

\section{Results}

\subsection{Analysis of Discursive Component}

\subsubsection{Macropropositions}

Dr Chan Lui Lee's essay is presented in a series of propositions, which are reduced to the following macropropositions:

1. Racial pride is not wrong if it does no harm, and so Malaysian politicians are upset over something harmless;

2. Chinese people are successful because of Chinese culture, which contains the ten characteristics;

3. Chinese people are resilient and independent of social welfare aid;

4. Chinese people are not a threat to other Malaysians;

5. Chinese people do not want political power but only to sustain themselves and improve their lives.

\subsubsection{Propositions}

Paragraph $1(\mathrm{P} 1)$ : Every race has their own pride. This is not a problem when it does not infringe upon the rights of 
other races. So there must be something wrong or suspicious in Malaysian politics for the politicians to discourage it.

P2: This is the truth - even if you may not like to hear it - about why Chinese people are so hardworking.

P3: We are so populous that we lack individuality. This keeps us from complacency.

P4: We are an ancient race. For continuing to exist throughout many years shows that the Chinese have evolved to survive, no matter the circumstances.

P5: Nobody is interested in the personal successes of individual Chinese, except their family members. Chinese people acknowledge their fallibility and vulnerability, so they do not take opportunities for granted. We do not expect favours from other races.

P6: We go all out for opportunities because there is nothing to lose in such endeavours, only gain. Because of this, Chinese people do not fear trying and thrive on taking such risks.

P7: From childhood, we are taught about the importance of money and how to manage it. The importance of money management is not a lesson that is taught across all cultures, because some see it as rude to make people feel conscious of the amount of money that has been spent on them, as if they are a financial burden. Most Chinese people can count because we have faced the realities of poverty and the economics of parenting from childhood.

P8: We acknowledge the impermanence of wealth.

P9: It is Chinese culture to encourage and expect each successive generation to achieve more than their predecessors. Therefore, Chinese culture emphasises excellence and innovation.

P10: Chinese culture is materialistic and judges the value of individuals by their material achievements and possessions. Chinese people do not have reservations about asking such questions, even if they appear to be insensitive. Because of this materialistic and competitive culture, non-Chinese people are considered luckier than Chinese people.

P11: We have been taught to make full use of their abilities, because even disabled people have shown that they have more remarkable talents than able-bodied people.

P12: It is ironic that even with the materialistic Chinese culture, Chinese people believe in charity to redeem themselves and as gratitude for good fortune. This is why our is progressive in all situations.

P13: Nobody has sympathy for the Chinese people. We accept this.

P14: No one is expected to perform favours for the Chinese people. We know this.

P15: The Chinese people are too populous for all to receive adequate welfare aid. We acknowledge this.

P16: Even with these obstacles, we still strive for better prospects so long as we are still alive.

P17: We do not take opportunities for granted. So excuse us for wanting to improve our lot in this country that we are attached to. It is our instinct for progress to bring more comfort into our lives.

P18: But look at the track record of the Chinese people.

P19: There is an established Chinese community in every country, but there is no instance of Chinese people establishing political dominance or control of a country where they have migrated to.

P20: So don't be afraid of the populous Chinese people outnumbering the majority race (Malay and Bumiputera Malaysians), we have no desire for socio-political control. We have emigrated from China and Chinese-governed countries so we do not seek another country to govern. We only elect representatives who are bound by duty to safeguard Chinese welfare and interests. We prefer to live ordinary lives and enjoy the rewards of their endeavours. We enjoy the company of people who have the same opinions as we do, even if they are of other races. We realise that our existence is only temporary, so we should collaborate for progress that benefits everyone.

\subsubsection{Local Meanings}

P1: “... wonder why the Malaysian politicians are so taboo about this?"

A situation description of Malaysia. In Malaysia, racial pride is prevalent for the Malays in the popular concepts of Ketuanan Melayu (Malay hegemony), Malay socio-political dominance and also through the use of religious Islamic pride (Heng, 1996). In contrast, racial pride is downplayed and also discouraged amongst the non-Malay Malaysians for fear of appearing unpatriotic or even seditious, as if it would indirectly challenge the leadership of the country that is overwhelmingly Malay (Balakrishnan, 2015; Ling, 2008).

P3: “... (like ballot boxes)...."

This is a reference to the outcome of GE13 when it was speculated that fake ballot boxes were smuggled into voting centres during electricity blackouts, which was why the ruling party that had lost popularity was allowed to remain as government and control the country (Reuters, 2013).

P3: “... We acknowledge that we are replaceable, thus we are not particularly 'special'...."

An allusion to the Malay and Bumiputra Malaysians who are considered "sons of the soil" (The Economist, 2013) and reign through Ketuanan Melayu. They hold a special position in Malaysia through a "social contract" (Ooi, 2005).

P5: “... We don't expect privileges to fall on our laps. No one owes us anything."

An allusion to the Malay and Bumiputra Malaysians who receive affirmative action and special allocations (The 
Economist, 2013). It also serves as a polarisation to distance the Chinese Malaysians from the Malay and Bumiputra Malaysians by saying that the Chinese people don't demand for the privileges that have been accorded to them as part of their social contract.

P7: “... What we take for granted like money management, ... is not something other cultures practice at home with their children. ... because it is rude to them. ..."

This is a presupposition that other Malaysian cultures don't have the same level of financial prudence and awareness, or consider such matters as being very important. What has been omitted here is the allusion towards Malay and Bumiputra Malaysians, given the historically lower socioeconomic status that they face (Balakrishnan, 2015).

P8: “... (urban myth?)....”

The author's hint of doubt in his assumption that wealth only stays in a family for three generations.

P9: “... Be KIASU.”

The word "kiasu" literally means "fear of losing" in Hokkien Chinese. The terms "kiasu" and "kiasi" ("fear of dying") are ubiquitous for the Hokkien Chinese and can also be considered a topos in the Malaysian context for competitiveness. However, its usage here can also be an allusion to the Chinese Malaysian Muslim convert, Ridhuan Tee Abdullah, who has made word "kiasu" a derogatory term to describe certain groups of Chinese Malaysians (Facebook, 2016).

P10: “... When you getting a boy? ...”

An implication of the sexist and patriarchal Chinese culture that historically favours and privileges boys over girls, and men over women. The births of boys are celebrated by their families, but the births of girls are considered to bring shame for their families. This is evident by the phenomenon of selective abortions of female foetuses which was once practiced in China (Junhong, 2001).

P11: “... People with no hands can do better than you (and the OKU artists do put us to shame)"

An implication of the ableism that manifests in Asian cultures. It presupposes that differently-abled bodies must be less capable than abled bodies. Examples of otherwise are taken as extraordinary cases and become material for inspiration to abled people.

P12: “... (not for profit) ...”

This message in parentheses shows that the author clearly wants to counter the societal presupposition that the Chinese people are unscrupulous and only care about material wealth (Durrasula \& Lysonski, 2010; The New York Times, 2013). However, including such a message in the essay has the opposite effect; it only serves to heighten the suspicion that the Chinese are indeed unscrupulous when it comes to the opportunity to prosper themselves.

P17: “... So, pardon us ... It is in our DNA to progress forward for a more comfortable life.”

This paragraph is based on the premise that the Chinese are being hindered in some way, and so it is a response to this presupposed situation with the message, "don't stop us because we only want progress."

P20: "Don’t be afraid of us overwhelming your majority, we are not looking to conquer. ..."

In reality, the Chinese are far from overwhelming the majority of Malay and Bumiputra Malaysians; the Chinese birth rate is declining at a faster rate than that of the Malays and Bumiputras (Chan, 2016). However, the Malay and the Bumiputra Malaysians fear and envy the socioeconomic success of the immensely wealthy Chinese (Crouch, 2001). This is a response to that fear and loathing of the Malay and Bumiputra Malaysians towards the socioeconomic dominance of the Chinese.

\subsubsection{Specific Linguistic Realisations}

P3: “... We are like photostat copies of each other. ..."

A Malaysian simile that has appropriated the Photostat brand into a verb, and then into a common noun upon itself. It serves to highlight the point that the Chinese people are so populous across the world, no Chinese individual is a unique person onto themselves.

P4: "We have been crawling all over this earth for far more centuries..."

The use of the word "crawling" illustrates the similarity between the Chinese people and insects. This is to serve as a comparison to the population of species of insects such as ants and bees, and to also compare the productivity and industrious nature between the Chinese people and such insects.

P4: “... We are like cockroaches. ..."

The author wants to illustrate the hardy nature of the Chinese people, yet he has chosen to use cockroaches over weeds, which also illustrate the point of hardiness. This can be connected to a deeper level of meaning by contextualising this simile to the Malaysian political situation.

By comparing the Chinese race to a vermin, the author is giving a subtle situation description of the position of the Chinese Malaysians in Malaysian society. Given that the essay was written after the 13th General Election, where it was shown that the opposition parties had received the overwhelming majority of Chinese votes, the Chinese Malaysians were considered ungrateful to the ruling government for not appreciating the ruling party by favouring them at the polls. More tellingly, it shows how the Chinese Malaysians have chosen not to align themselves with a political party that has 
marketed itself as the champion of preserving and extending Malay rights (Sinar Harian, 2013; Utusan Online, 2013).

Moreover, given the Chinese Malaysians' position in Malaysia as the racial group that contrasts sharply against the Malay Malaysians in terms of socioeconomic position, wealth and income, the Chinese are considered the vermin of the country for depriving the Malays of socioeconomic opportunities and hence, making the Malays feel like second-class citizens in their own motherland in socioeconomic terms.

Due to these two factors, the idea that these ungrateful Chinese must be "exterminated" from the country arose, which is echoed through political chants of "Cina balik China" (The Malay Mail Online, 2013). But just as cockroaches are hard to kill, the author takes this trait as something to be proud of, and draws it parallel to his own race.

P5: "NOBODY cares if we succeed as individuals or not. ..."

P5: “... No one owes us anything." P13: "Nobody pities us. ..." P14: "No one owes us anything. ..."

This is a topos that runs throughout the essay. It serves to highlight the situation of the Chinese as the unwanted race; yet, it is also implied as a face-threatening act of snubbing the local government's affirmative action policies which has favoured Malay and Bumiputra Malaysians over all other races (The Economist, 2013).

P8: "We acknowledge life cycles. ... Then we are back to square one. ..."

The usage of "life cycles" serves to illustrate the impermanence and transience of money. But is also a reminder of hope, because using this same philosophy, if money can easily slip away, one can also regain the lost wealth.

P9: “... Be smarter. Be stronger. Be faster. ... Be everything you can be in this lifetime. ..."

This is another topos in the essay that talks about the pressure on the Chinese to continually strive to be better and outdo other people. It emphasises on material achievement instead of intrinsic or spiritual contentment and inner happiness from the Chinese (Durrasula \& Lysonski, 2010).

P10: “... It NEVER ENDS... so, we can't stop chasing the illusive train - we are damned to a materialistic society. ..."

The use of "illusive train" was intended by the author to show that the chase for material success - being the "train" - is an imaginary achievement. One easily becomes disillusioned by material wealth after that, because human lives are complex and require more than just material wealth, success and something to brag about. Chinese will have neglected on developing and fulfilling other aspects of their life.

P19: "Every country has a Chinatown ..."

A synecdoche for settlements of the Chinese diaspora in countries outside Far East Asia.

\subsection{Analysis of Cognitive Component}

\subsubsection{Context Model}

Setting: The essay was published online, on social media and news websites after GE13. The essay was mostly shared within Malaysia, with a Malaysian audience.

Events/Participants: Malaysians with access to internet and social media. This means that only Malaysians who can afford an internet service subscription, and Malaysians who are users of social media have access to the essay. The essay may also have been distributed in the form of email, for Malaysians who do not use social media.

Action/Discourse: It is a call to action for Chinese Malaysians and non-Chinese Malaysians. Whilst for non-Chinese Malaysian readers it is the request for accommodation of the existence of the Chinese Malaysians, to the Chinese Malaysian readers it is a source of improved self-esteem, confidence and pride in the Chinese identity and the justification for the Chinese way of life.

Cognition: Whist it mostly contains positive emotions for the Chinese Malaysians, non-Chinese Malaysians and some Chinese Malaysians may not be appreciative of the essay. That is why it has been categorised as satire in Ramesh Rajaratnam's version of it in Malaysiakini (2015).

\subsubsection{Event Model}

Setting: August 2013. A time when the 13th General Election just ended in Malaysia, when Chinese were seen as the bane of the country especially for their enmity against the ruling political party (Sinar Harian, 2013; Utusan Online, 2013).

Participants: Audience consists of Chinese Malaysians, and Malaysians of other races. Author is Chinese Malaysian, and the voice is as if intended for non-Chinese Malaysians.

Event or Action: The feeling and environment of hostility towards Chinese Malaysians, especially from Malays and Bumiputras. Because of this environment, this essay was intended for impressing upon the Malays and Bumiputras about the virtues of the Chinese, and what they stand to lose if they continue their hostility.

Circumstances: In the aftermath of the 13th General Election of Malaysia, it was revealed that the majority of support from Chinese voters had shifted to the opposition. Henceforth the Chinese were seen as ungrateful to the ruling party, because it was claimed that the Chinese received a lot of rights from the ruling government, and their lifestyle was accommodated for in a country where Islam was the official religion (Sinar Harian, 2013; Utusan Online, 2013).

General opinion towards event: The circumstances resulted in racial tensions, especially between the Malay Islamists and the non-Muslim Chinese. Malays and Bumiputras were hostile towards the Chinese because of the Chinese cultural 
affinity for eating pork, drinking liquor and gambling, all of which were prohibited by Islam (Heng, 1996). Hence the Chinese were scapegoated as the enemies of Islam, together with Jews and Christians. It was even speculated that the Chinese wanted to instate a Chinese prime minister, and do away with Ketuanan Melayu and Malay special privileges which was a threat to the current status quo (Balakrishnan, 2015; Fernandez, 2015).

Analysis of data and the reporting of the results of those analyses are fundamental aspects of the conduct of research. Accurate, unbiased, complete, and insightful reporting of the analytic treatment of data (be it quantitative or qualitative) must be a component of all research reports. Researchers in the field of psychology use numerous approaches to the analysis of data, and no one approach is uniformly preferred as long as the method is appropriate to the research questiqns being asked and the nature of the data collected. The methods used must support their analytic burdens, including robustness to violations of the assumptions that underlie them, and they must provide clear, unequivocal insights into the data.

\subsection{Analysis of Social Component}

\subsubsection{Ideology Analysis}

a. Membership

Chinese people, who practice Chinese culture and the attributes as listed in the essay.

\section{b. Activities}

Chinese people only participate in the private sector economy, and do not take up positions in the government. They are not interested in politics.

\section{c. Aims}

Chinese people only want to enrich themselves materially so that they live comfortable lives, and improve their quality of lives successively.

\section{d. Norms}

The materialistic nature of the Chinese is both good and bad. Chinese judge fellow Chinese and other people based on their materialistic accomplishments, which is bad because it puts excessive pressure on achieving such success at all costs. However, this creates the competitive nature of the Chinese which makes them hard to feel content at all.

\section{e. Relations}

Friends are people who think like us, share our opinions. Enemies are those who get in the way of the Chinese way of life. The Chinese Malaysians in society are just a minority, but they control a significant portion of the economy by virtue of their wealth that they have accumulated.

\section{f. Resources}

The Chinese have their competitive spirit, early lessons on money management and endurance for survival as their legacy. What they don't have is the sympathy from other races, and minimal government assistance.

\subsubsection{The Ideological Square}

Applying the Ideological Square to the ideologies uncovered in the essay, it is evident that most of the essay shows two strategies which have been used by the author. The author emphasises positive attitudes about the Chinese race, and deemphasises positive attitudes about non-Chinese Malaysians. There are also hints of emphasising negative attitudes surrounding non-Chinese Malaysians, such as the reference to affirmative action policies for Malays and Bumiputra Malaysians.

\section{Discussion}

The analysis of discursive components in the essay confirmed the presence of Chinese racial pride, and the idea that the Chinese race is superior to the Malay race in Malaysia. However, examination of the cognitive and social components in "Proud to be born a Chinese" show that Chinese racial pride is reinforced as a result of socio-political events where the Chinese racial identity was devalued in Malaysia.

These aspects could not have been discovered with just a cursory reading of the text. The macropropositions condensed the meaning of the essay, whilst the propositions provided the essence of each idea elaborated in the paragraphs. These two steps made the process of looking for Chinese racial pride and identity superiority over other races much easier to identify.

Implications, presuppositions, allusions, topoi, specific word choices and the strategic use of linguistic devices were revealed in the analysis of local meanings and specific linguistic realisations of "Proud to be born a Chinese". This section provided clear indicators that the Chinese racial identity, marked by Chinese culture, was conveyed as being superior to the identities of other races specifically Malays and Bumiputras. The Malays and Bumiputras were frequently alluded to for their presupposed dependence on affirmative action by the author Dr. Chan-Lui Lee, and he used this topos to create a polarisation between this group and the Chinese race. Moreover, a distinction was made between the Chinese people and people from other races through the assumption that teaching financial management to children was unique to the Chinese culture. This point was made into one of the ten merits of the Chinese people, to explain why the Chinese people appeared so outstanding in comparison to people of other races. The explanation also serves as a telling assumption that highlights the perceived notion of racial superiority that is embodied in the essay. 
These characteristics of the essay show the clear use of group identity in a multicultural country to facilitate the creation of "faultlines" with another group identity (Lau \& Murnighan, 1998; Thatcher \& Patel, 2011 as cited by Feitosa, Salas $\&$ Salazar, 2012).

The results of the analysis on the cognitive components, namely the context model and event model, provides contextual information on the essay. The timing of the writing, its location, events and actions surrounding "Proud to be born a Chinese" are insights into the circumstances that inspired Dr. Chan-Lui Lee to write the text. It becomes evident that the essay was written as a response to the socio-political environment which had become hostile to the Chinese Malaysians for the outcome of the 13th General Election in Malaysia. Under the strategies of racial politics, the Chinese people were portrayed by Malaysian media to be disobedient and ungrateful to the ruling government for not aligning themselves with a certain political body. Moreover, the Chinese people had been perceived to reject the social contract, and to be a threat to the status quo of Ketuanan Melayu that had been the source of pride for Malay Malaysians. With these elements of context in mind, it becomes clear that the notion of a Malaysian national identity, where Malaysians de-emphasise their racial identity in favour of a common "Malaysian Malaysia" identity (Abdullah, 2004), is not yet possible because of the racial stereotyping and racial prejudice that has inspired the conception of "Proud to be born a Chinese". Just as the Malay assert and emphasise their Malay racial heritage and Malay racial hegemony through Ketuanan Melayu, the pressure on Chinese Malaysians who are vilified for being Chinese has likewise inspired them to assert their Chinese racial identity even more over their identity of being Malaysian. This point is exemplified in Heng's (1996) study which explained that as the Malays adhered to stricter Islamic rituals and norms, the Chinese Malaysians become more aware of their racial and cultural distinctiveness from the Malays such as their dietary norms: the consumption of alcohol and pork.

This position of the construction of identity is reflected in the ideologies embedded in the text. As part of the social component, the ideology analysis reveals the boundaries of identity construction in the Chinese Malaysian identity. Through this process, the next step of ideology analysis inspects the "Us vs. Them" perspective that guides the message of Dr. Chan-Lui Lee's essay. "Us" refers to the Chinese Malaysians, and "Them" refers to the non-Chinese Malaysians with the implied emphasis on Malay Malaysians. These messages combined with the other messages from the essay form the three aspects that have been described in the ideological square. The positive traits of the Chinese race are emphasised, and generalised to describe the Chinese Malaysians collectively. Even behaviour and attitudes usually associated with negativity such as materialism and risk-taking are painted in a positive light to become coveted traits, because these are the stereotypical traits of the Chinese. On the other hand, the positive traits of the non-Chinese Malaysians are not mentioned at all in the essay. Moreover, non-Chinese Malaysians are negatively portrayed as being dependent on affirmative action, and not being as ambitious or driven to succeed as the Chinese because they are not as materialistic and aware of the importance of financial management.

When all the facets of the analysis are combined, the results show that the emphasis on Chinese racial identity is greater than the affinity for the Malaysian national identity because of the socio-political context of Malaysia, which is reflected in the essay. Chinese racial pride has become a form of resistance against the identity politics of Malaysia that portrays the Chinese Malaysians as the nemesis of Malay Malaysians. The collective identities of Chinese-ness and Malaysianness become the central point of a struggle for socio-political power (Klandermans, 2014) in the country. Just as the Chinse racial identity is perceived to be the antithesis of the Malaysian national identity (Callahan, 2003), it is in this way that the essay "Proud to be born a Chinese" is a retaliation against these events and circumstances that plague Malaysia.

\section{Conclusion}

These findings indicate that the success of national unity in Malaysia is unstable. As the Malay people have emphasised their Malay pride and Malay racial hegemony and the Chinese people have reacted by emphasising their own racial identity and pride, the emphasis on the "Malaysian Malaysia" identity has been reduced to a great extent. Neither of these two races are willing to cede their racial pride in favour of a common Malaysian national identity. This creates deep polarisation between the two groups; the "Us vs. Them" mentality that threatens the socio-political harmony of the country. However, there is also hope in the dynamic nature of the construction of identity. Just as socio-political circumstances can increase the identification with racial identity amongst Malaysians, a change in the situation can convince Malaysians to gradually decrease their identification with race, and identify more with the "Malaysian Malaysia" identity that will cultivate a landscape of racial and cultural harmony once more.

As this study is purely qualitative in nature, it is recommended that future research on this matter incorporate both qualitative and quantitative methods to reflect a more accurate picture of the situation regarding racial identity and national identity. Devising the instruments for such a comprehensive research would be useful for application to various countries, where the environment of racial polarisation and success of national unity can be studied. One example is to conduct a corpus CDA on the news reports regarding the shift in Chinese Malaysian votes in 2013, which should include not just English-language news but also news from other languages as each newspaper and tabloid will construct a different event model of the phenomenon.

Another suggestion for the future direction of research regarding the prioritisation and emphasis on certain dimensions of identity in the construction of identity is to utilise Norman Fairclough's (2015) approach of CDA, which focuses on the theme of social conflict in the Marxist sense. Just as this report uncovered the use of racial identity as a form of resistance against the discrimination of that identity, future studies should then be aimed towards the emancipation of marginalised people whose dimensions of identity are discriminated against. 


\section{References}

Abdullah, F. S. (2004). Prolegomena to a discursive model of Malaysian national identity. Systemic Functional Linguistics and Critical Discourse Analysis: Studies in Social Change (pp. 123-138).

Abdullah, M. R. T. (2016, April 11). 26 Sifat Ultra Kiasu (Sinar Harian 11.4.16). Facebook. Retrieved from https://www.facebook.com/ridhuantee/posts/996955070395576

Ainsworth, S., \& Hardy, C. (2004). Critical discourse analysis and identity: Why bother? Critical Discourse Studies, 1(2) (pp. 225-259).

Bakar, Z. (2013, May 7). Apa lagi orang Cina mahu? Utusan Online. Retrieved from http://ww1.utusan.com.my/utusan/Pilihan_Raya/20130507/px_03/Apa-lagi-orang-Cina-mahu

Balakrishnan, N. (2015, October 5). When Malaysian Leaders Call The Chinese Community "Babi", "Luckiest" And "Rude". SAYS.com. Retrieved from http://says.com/my/news/threats-and-words-of-wisdom-to-the-chinese-communityfrom-malaysian-politicians

Budianta, M. (2000). Discourse of cultural identity in Indonesia during the 1997-1998 monetary crisis. Inter-Asia Cultural Studies, 1(1) (pp. 109-128).

Callahan, W. A. (2003). Beyond cosmopolitanism and nationalism: diasporic Chinese and neo-nationalism in China and Thailand. International Organization, 57(03), 481-517.

Chan, A. (2016, February 16). Drastic fall in Chinese birth rate. The Star Online. Retrieved from http://www.thestar.com.my/news/nation/2016/02/16/drastic-fall-in-chinese-birth-rate-dept-of-statistics-population-ratiowill-fall-to-just-184-by-2040/

Crouch, H. (2001). Managing ethnic tensions through affirmative action: The Malaysian experience. Social Cohesion and Conflict Prevention in Asia: Managing Diversity Through Development, 225-262.

DePolo, J. R. (2010). Discursive Transformation and the Reconstruction of Identity: A Critical Discourse Analysis of African American Student Texts.

Durvasula, S., \& Lysonski, S. (2010). Money, money, money - How do attitudes toward money impact vanity and materialism? - The case of young Chinese consumers. Journal of Consumer Marketing, 27(2), 169-179.

Feitosa, J., Salas, E., \& Salazar, M. R. (2012). Social identity: Clarifying its dimensions across cultures. Psihologijske Teme, 21(3), 527-548.

Feng, B. (2013, December 20). Chinese Respondents Top Materialism Poll. The New York Times. Retrieved from http://sinosphere.blogs.nytimes.com/2013/12/20/chinese-respondents-top-materialism-poll/

Fernandez, J. (2015, September 6). Shahbudin: Chinese Prime Minister a ghost story. Free Malaysia Today. Retrieved from http://www.freemalaysiatoday.com/category/nation/2015/09/06/shahbudin-chinese-prime-minister-a-ghost-story/

Helland, K. I. (2015). Multilingualism, Identity, and Ideology in Popular Culture Texts: A Multimodal Critical Discourse Analysis.

Hernández, A. (2008). SFL and CDA: Contributions of the analysis of the transitivity system in the study of the discursive construction of national identity (case study: Gibraltar). The Linguistics Journal, 3(3) (pp. 160-175).

Heyes, C. (2002). Identity Politics.

Heng, P. K. (1996). Chinese Responses to Malay Hegemony in Peninsular Malaysia 1957-96. Southeast Asian Studies, 34(3), 32-55.

Jones, S. R., McEwen, M. K., \& Abes, E. S. (2007). Reconceptualizing the Model of Multiple Dimensions of Identity: The role of meaning-making capacity in the construction of multiple identities. Journal of College Student Development, 48(1) (pp. 1-22).

Junhong, C. (2001). Prenatal sex determination and sex-selective abortion in rural central China. Population and Development Review, 27(2), 259-281.

Klandermans, P. G. (2014). Identity politics and politicized identities: Identity processes and the dynamics of protest. Political Psychology, 35(1) (pp. 1-22).

Lau, D. C., \& Murnighan, J. K. (1998). Demographic diversity and faultlines: The compositional dynamics of organizational groups. Academy of Management Review, 23(2), 325-340.

Ling, H. S. (2008). Negotiating Malaysian Chinese Ethnic and National Identity Across Borders (Doctoral dissertation, Ohio University).

Liu, J. H., Lawrence, B., Ward, C., \& Abraham, S. (2002). Social representations of history in Malaysia and Singapore: On the relationship between national and ethnic identity. Asian Journal of Social Psychology, 5(1) (pp. 3-20).

Liu, M. (2013). Representational Pattern of Discursive Hegemony. Open Journal of Modern Linguistics, 3(02), 135.

Malaysian Elections. Reuters. Retrieved on May 25, 2016 from http://live.reuters.com/Event/Malaysian_elections

Ooi, J. (2005, August 16). Social Contract: 'Utusan got the context wrong'. Screenshots. Retrieved from https://web.archive.org/web/20051030165436/http://www.jeffooi.com/archives/2005/08/the_nst_should.php 
Pieterse, J. N. (2004). Ethnicities and multiculturalisms: Politics of boundaries. Ethnicity, Nationalism, and Minority Rights (pp. 27-49).

Rajaratnam, R. (2015, February 4). 10 reasons why 'puak Cina' succeed in M'sia. Malaysiakini. Retrieved from https://www.malaysiakini.com/news/288214

Sinar Harian (2013, May 8). Mahathir: PRU13 bukti 'tsunami Cina, Melayu tamak. Sinar Harian. Retrieved from http://www.sinarharian.com.my/politik/mahathir-pru13-bukti-tsunami-cina-melayu-tamak-1.157945

Tan, C. B. (1988). Nation-building and being Chinese in a Southeast Asian state: Malaysia. Changing Identities of the Southeast Asian Chinese Since World War II, 139.

The Economist (2013, April 27). A Never Ending Policy. The Economist. Retrieved from http://www.economist.com/news/briefing/21576654-elections-may-could-mark-turning-point-never-ending-policy

The Malay Mail Online (2013, July 31). Headmistress has apologised for 'Balik India, China' remark, claims MIC. The Malay Mail Online. Retrieved from http://www.themalaymailonline.com/malaysia/article/headmistress-has-apologisedfor-balik-india-china-remark-claims-mic-leader

van Dijk, T. A. (1999). Context models in discourse processing. The Construction of Mental Representations During Reading, 123-148.

van Dijk, T. A. (2007). Macro contexts. Discourse and International Relations, 3-26.

Van Dijk, T. A. (2013). Ideology and discourse. The Oxford Handbook of Political Ideologies, 175-196.

van Dijk, T. A. (2014). Discourse, cognition, society. The Discourse Studies Reader: Main Currents in Theory and Analysis (pp. 388).

van Dijk, T. A. (2015) Critical Discourse Studies: A Sociocognitive Approach. In Wodak, R., \& Meyer, M. (Eds.). (2015). Methods of Critical Discourse Studies (pp. 63-74). Sage.

Wodak, R., de Cilia, R., \& Reisigl, M. (2009). The Discursive Construction of National Identity. Edinburgh University Press.

World of Buzz. (2015, October 5). Indian Malaysian Wrote About Chinese People And It Was Inspiring. World of Buzz. Retrieved from http://www.worldofbuzz.com/indian-malaysian-wrote-about-chinese-people-and-it-was-inspiring/ 